\title{
Kinetic processes and Phase-transition of CVD processes for $\mathrm{Ti}_{3} \mathrm{SiC}_{2}$
}

\author{
Jürgen Geiser and Robert Röhle \\ Humboldt-Universität zu Berlin, \\ Department of Mathematics, \\ Unter den Linden 6, D-10099 Berlin, Germany \\ geiser@mathematik.hu-berlin.de
}

\begin{abstract}
In this paper we present a kinetic model based on numerical simulations of a chemical vapor deposition (CVD) process.

We discuss a model that is based on kinetics of the deposition rates to the material. Such a simple model can explain the experimental results. Based on experiments with $\mathrm{Ti}_{3} \mathrm{SiC}_{2}$ we verify our model. Here different processes of ionized $\mathrm{Ti}^{+}, \mathrm{Ti}^{++}$and $C$ are important to achieve our stoichiometry. The numerical methods are based on iterative schemes to solve coupled and nonlinear differential equations. The results are discussed with physical experiments to give a valid model for the assumed growth of thin layers.
\end{abstract}

Keywords: PE-CVD process, pathway model, convection-diffusion equations. AMS subject classifications. 35K25, 35K20, 74S10, 70G65.

\section{Introduction}

We motivate our studying on simulating a thin film deposition process that can be done with plasma enhanced chemical vapor deposition (PECVD) processes. In the last years, due to the research in producing high temperature films by depositing of low pressure, processes have increased. The interest on standard applications to $\mathrm{TiN}$ and $\mathrm{TiC}$ are immense but recently also deposition with new material classes known as MAX-phases are important. The MAX-phases are nanolayered terniar metal-carbides or -nitrides, where $M$ is a transition metal, $A$ is an A-group element (e.g. $\mathrm{Al}, \mathrm{Ga}, \mathrm{In}, \mathrm{Si}$, etc.) and $X$ is $C$ (carbon) or $N$ (nitrogen).

We present a model for the kinetic processes of the precursor gases in a low temperature and low pressure plasma. The model can be extended as a pathway model, see [1], to achieve the deposition rates of the stoichiometry 3Ti,Si and $2 C$.

We take into account the kinetics of CVD processes in the reactor and the less retardation of molecules, which are not treated by the plasma.

The model is discussed as a kinetic model with systems of reaction equations. The paper is outlined as follows. 
In section 2 we present our mathematical model and a possible reduced model for the further approximations. In section 3 we present the underlying analysis of the numerical methods. The numerical experiments are given in Section 4. In the contents, that is given in Section 5, we summarize our results.

\section{Mathematical Model}

In the following, the models are discussed in two directions of qualitative and quantitative models:

1. Reaction-diffusion equations, see [7] (qualitative results);

2. Pathway model, see [1] (quantitative results).

In the models we assume a moderate Knudsen Number $(K n<1)$, so that we can deal with continuous descriptions. The Knudsen Number (Kn) which is the ratio of the mean free path $\lambda$ over the typical domain size $L$.

\subsection{Transport Model}

Here we deal with a transport model and continuum flow of our gaseous and ionized species. Such a mass transport can be treated with a convection-diffusion reaction equation, when assuming low temperatures and low pressures. So we take into account the balance of impulse and energy.

Three basic equations describe the conservation of mass, momentum and energy, that are sufficient to describe the gas transport in the reactors, see [14].

We concentrate on the conservation of mass and assume that the energy and momentum is conserved, see [7]. Therefore the continuum flow can be described as a convection-diffusion equation given as:

$$
\begin{gathered}
\frac{\partial}{\partial t} c+\nabla F-R_{g}=0, \text { in } \Omega \times[0, T] \\
F=\boldsymbol{v} c-D \nabla c, \\
c(x, t)=c_{0}(x), \text { on } \Omega, \\
c(x, t)=c_{1}(x, t), \text { on } \partial \Omega \times[0, T],
\end{gathered}
$$

where $c$ is the molar concentration and $F$ the flux of the species. $D$ is the diffusion of the species, $\boldsymbol{v}$ is the velocity and $R_{g}$ is the reaction term. The initial value is given as $c_{0}$ and we assume a Dirichlet Boundary with the function $c_{1}(x, t)$ sufficient smooth.

\subsection{Pathway model}

If we assume a simple consideration of the rates in the reactor, we can also deal with a pathway model. Such a model takes into account the rates of the different species, here for example $\mathrm{Ti}^{+}, \mathrm{Si}^{+}, \mathrm{C}$.

We are only interested on a quantitative result and verify with physical experiments. 
Single Pathway

Here our model is based on the following pathway model of [1], see Figure 1.

\section{Multi Pathway}

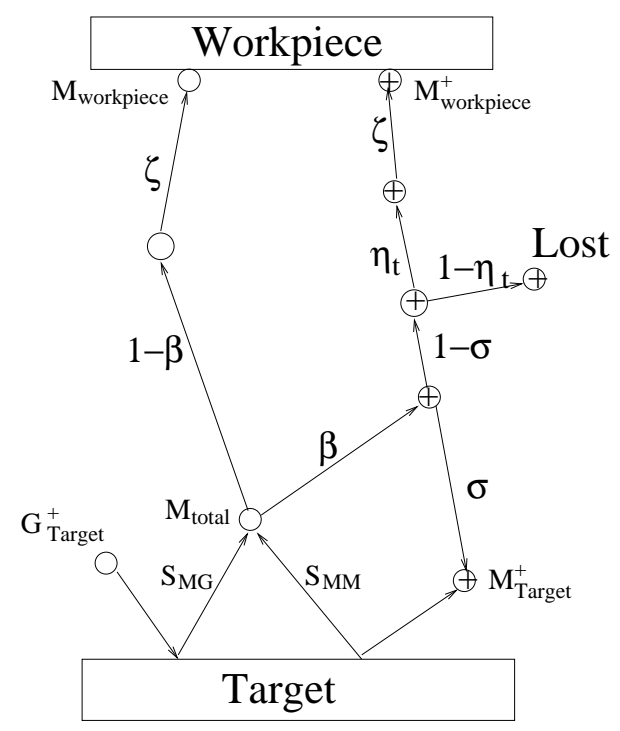

Fig. 1. Pathway model (Christie 2005).

Here our model is based on a generalization of a single species pathway model of [1], see Figure 2.

Remark 1. We are interested on simulating the loss rates of the processes in the plasma enhanced process.

\subsection{Kinetic: Chemical Reactions}

The kinetic processes involve reactions with the following precursor gases. Tetramethylsilane $\left(\mathrm{CH}_{3} \mathrm{SiCl}_{3}\right)$ :

According to Zhang and Huettinger (see [25]) and the available data (see Table 1) we first of all propose the following reaction mechanism for the CVD of $\mathrm{SiC}$ from Methyltrichlorosilane:

$$
\begin{aligned}
& \mathrm{CH}_{3} \mathrm{SiCl}_{3} \stackrel{k_{1}}{\longrightarrow} \cdot \mathrm{CH}_{3}+\cdot \mathrm{SiCl}_{3} \\
& \cdot \mathrm{CH}_{3}+\mathrm{H}_{2} \stackrel{k_{2}}{\longrightarrow} \mathrm{CH}_{4}+\cdot \mathrm{H}
\end{aligned}
$$




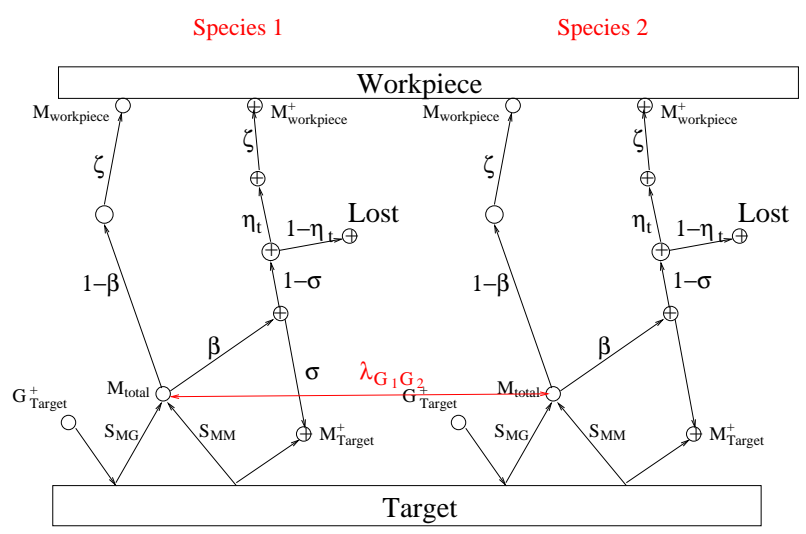

Fig. 2. Pathway model.

$$
\begin{aligned}
& \text {. } \mathrm{CH}_{3}+\mathrm{CH}_{3} \mathrm{SiCl}_{3} \stackrel{\mathrm{k}_{3}}{\longrightarrow} \mathrm{CH}_{4}+\mathrm{Cl}_{3} \mathrm{SiC} \mathrm{H}_{2} \\
& \cdot \mathrm{SiCl}_{3}+\mathrm{HCl} \stackrel{k_{4}}{\longrightarrow} \mathrm{HSiCl}_{3}+\dot{\mathrm{Cl}} \\
& 2 \cdot \mathrm{SiCl}_{3} \stackrel{k_{5}}{\longrightarrow} \mathrm{SiCl}_{4}+\ddot{\mathrm{SiCl}} 2 \\
& \mathrm{HSiCl}_{3} \stackrel{k_{6}}{\longrightarrow} \ddot{S i C l}_{2}+\mathrm{HCl} \\
& \mathrm{SiCl}+\cdot \mathrm{H}^{\stackrel{k_{7}}{\longrightarrow}} \mathrm{SiCl}_{3}+\mathrm{HCl} \\
& \ddot{\mathrm{SiCl}} \mathrm{Cl}_{2}+\mathrm{CH}_{4} \stackrel{k_{8}}{\longrightarrow} \mathrm{Cl}_{\mathrm{SiCH}}+\mathrm{HCl} \\
& 2 \mathrm{Cl}_{\mathrm{SiCH}} \stackrel{k_{9}}{\longrightarrow}\left[\dot{S} i \mathrm{HClC} \mathrm{CH}_{2}\right]_{2}
\end{aligned}
$$

The last reaction ends up in the deposition of $\mathrm{SiC}$. The reaction constants $k_{1}$ to $k_{9}$ are given in Table 1 , where $R=8.314472 \frac{\mathrm{J}}{\mathrm{mol}}$.

According to the previous mechanism we formulate the deposition of $\mathrm{SiC}$ via Tetramethylsilane:

$$
\begin{aligned}
& \mathrm{Si}\left(\mathrm{CH}_{3}\right)_{4} \rightarrow \cdot \mathrm{CH}_{3}+\cdot \mathrm{Si}\left(\mathrm{CH}_{3}\right)_{3} \\
& \text {. } \mathrm{CH}_{3}+\mathrm{H}_{2} \rightarrow \mathrm{CH}_{4}+\cdot \mathrm{H} \\
& . \mathrm{CH}_{3}+\mathrm{Si}\left(\mathrm{CH}_{3}\right)_{4} \rightarrow \mathrm{CH}_{4}+\left(\mathrm{CH}_{3}\right)_{3} \mathrm{SiC} \mathrm{CH}_{2} \\
& . \mathrm{Si}\left(\mathrm{CH}_{3}\right)_{3}+\mathrm{H}_{2} \rightarrow \mathrm{HSi}\left(\mathrm{CH}_{3}\right)_{3}+\dot{\mathrm{H}} \\
& 2 \cdot \mathrm{Si}\left(\mathrm{CH}_{3}\right)_{3} \rightarrow \mathrm{Si}\left(\mathrm{CH}_{3}\right)_{4}+\ddot{\mathrm{Si}}\left(\mathrm{CH}_{3}\right)_{2} \\
& \mathrm{Si}\left(\mathrm{CH}_{3}\right)_{4}+\mathrm{H}_{2} \rightarrow \mathrm{HSi}\left(\mathrm{CH}_{3}\right)_{3}+\mathrm{CH}_{4} \\
& \mathrm{HSi}\left(\mathrm{CH}_{3}\right)_{3} \rightarrow \ddot{\mathrm{Si}}\left(\mathrm{CH}_{3}\right)_{2}+\mathrm{CH}_{4} \\
& \ddot{S} i\left(\mathrm{CH}_{3}\right)_{2} \rightarrow \dot{\mathrm{S} i} \mathrm{H}_{2} \dot{\mathrm{C}} \mathrm{H}_{2}
\end{aligned}
$$

The last reaction ends up in the deposition of $\mathrm{SiC}$. 


\begin{tabular}{c|c|c|c}
$k_{i}$ & rate & reaction order & source \\
\hline$k_{1}$ & $10^{18} \mathrm{~s}^{-1} \cdot \exp \left(-408 \frac{\mathrm{kJ}}{\mathrm{mol}} /(R T)\right)$ & 1 & {$[18]$} \\
$k_{2}$ & $1.45 \cdot 10^{-11} \frac{\mathrm{cm}^{3}}{\mathrm{~mol} \cdot \mathrm{s}} \cdot \exp \left(-56 \frac{\mathrm{kJ}}{\mathrm{mol}} /(R T)\right)$ & 2 & {$[19]$} \\
$k_{3}$ & $1.26 \cdot 10^{-11} \frac{\mathrm{cm}^{3}}{\mathrm{~mol} \cdot \mathrm{s}} \cdot \exp \left(-48 \frac{\mathrm{kJ}}{\mathrm{mol}} /(R T)\right)$ & 2 & {$[20]$} \\
$k_{4}$ & $1.54 \cdot 10^{-20} \frac{\mathrm{cm}^{3}}{\mathrm{~mol} \cdot \mathrm{s}} \cdot \exp \left(-7.8 \frac{\mathrm{kJ}}{\mathrm{mol}} /(R T)\right)$ & 2 & {$[21]$} \\
$k_{5}$ & $10^{9} \frac{\mathrm{cm}^{3}}{\mathrm{~mol} \cdot \mathrm{s}}$ & 2 & {$[22]$} \\
$k_{6}$ & $4.39 \cdot 10^{14} \mathrm{~s}^{-1} \cdot \exp \left(-301 \frac{\mathrm{kJ}}{\mathrm{mol}} /(R T)\right)$ & 1 & {$[23]$} \\
$k_{7}$ & $2.3 \cdot 10^{-11} \frac{\mathrm{cm}^{3}}{\mathrm{~mol} \cdot \mathrm{s}} \cdot \exp \left(-40 \frac{\mathrm{kJ}}{\mathrm{mol}} /(R T)\right)$ & 2 & {$[24]$} \\
$k_{8}$ & $10^{2} \frac{\mathrm{cm}^{3}}{\mathrm{~mol} \cdot \mathrm{s}}$ & 2 & {$[22]$} \\
$k_{9}$ & $10^{9} \frac{\mathrm{cm}}{\mathrm{mol} \cdot \mathrm{s}}$ & 2 & {$[22]$}
\end{tabular}

Table 1. Reaction constants for the formation of $\mathrm{SiC}$ from Methyltrichlorosilane

Titanium precursor:

We will now investigate the consecutive decay of Tetraethyltitanium which can lead to the deposition of TiC:

$$
\begin{aligned}
& \mathrm{Ti}\left(\mathrm{CH}_{2} \mathrm{CH}_{3}\right)_{4} \rightarrow \cdot \mathrm{Ti}\left(\mathrm{CH}_{2} \mathrm{CH}_{3}\right)_{3}+\cdot \mathrm{CH}_{2} \mathrm{CH}_{3} \\
& \cdot \mathrm{Ti}\left(\mathrm{CH}_{2} \mathrm{CH}_{3}\right)_{3} \rightarrow \ddot{\mathrm{Ti}}\left(\mathrm{CH}_{2} \mathrm{CH}_{3}\right)_{2}+\mathrm{CH}_{2} \mathrm{CH}_{3} \\
& \ddot{\mathrm{Ti}}\left(\mathrm{CH}_{2} \mathrm{CH}_{3}\right)_{2} \rightarrow \cdot \ddot{\mathrm{T} i C H} \mathrm{CH}_{2}+\cdot \mathrm{CH}_{2} \mathrm{CH}_{3}
\end{aligned}
$$

Additionally we can use a titanium precursor shown in Figure 3. Here we can step by step separate the $\mathrm{CH}_{3}$ groups.

The optimization of this processes is used to derive $\mathrm{Ti}_{3} \mathrm{SiC}_{2}$ at last.<smiles>CC1C(C)C(C)C([I+](C)(C)C)C1C</smiles>

Fig. 3. Cp*TiMe3 or (Trimethyl)pentamethylcyclopentadienyltitanium(IV) 
The apparatus is given as in Figure 4, where the sources are given.

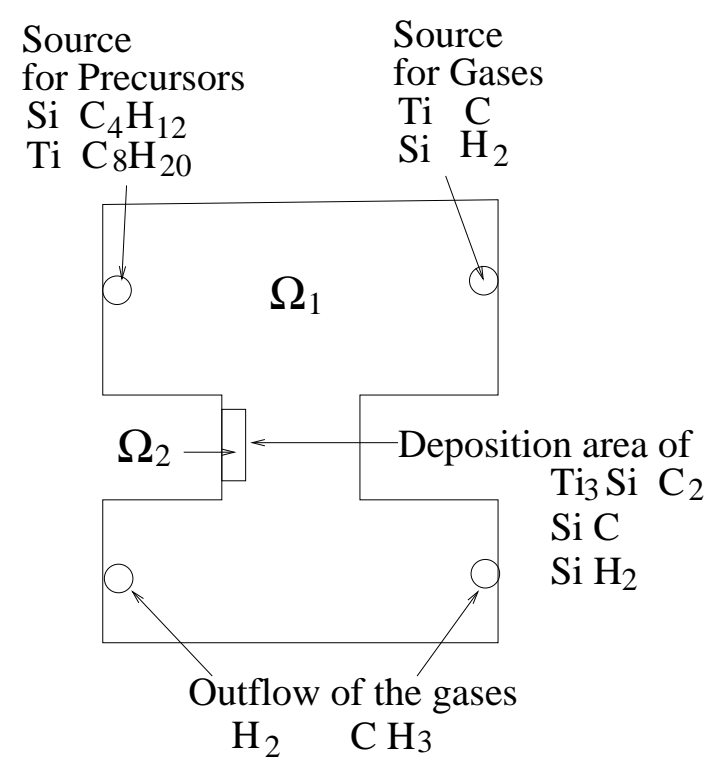

Fig. 4. Real-life domain of the CVD apparatus and their inflow- and outflow sources.

\section{Iterative Methods}

We deal with the method of successive approximations, or Picard iteration, which provides a method that can, in principle, be used to solve any initial value problem.

$$
y=f(t, y), y\left(t_{0}\right)=y_{0}
$$

It starts by observing that any solution to (24) must also be a solution to

$$
\phi(t)=y 0+\int_{t_{0}}^{t} f(s, \phi(s)) d s
$$

which is proofed, see [12] and [13], and then iteratively constructing a sequence of solutions that get closer and closer to the actual solution of (25).

The successive approximations are all based on the integral equation (25), as follows:

$$
\phi_{0}(t)=y 0
$$




$$
\begin{gathered}
\phi_{1}(t)=y_{0}+\int_{t_{0}}^{t} f\left(s, y_{0}\right) d s \\
\phi_{2}(t)=y_{0}+\int_{t_{0}}^{t} f\left(s, \phi_{1}(s)\right) d s \\
\phi_{3}(t)=y_{0}+\int_{t_{0}}^{t} f\left(s, \phi_{2}(s)\right) d s
\end{gathered}
$$

and in general

$$
\phi_{k}(t)=y_{0}+\int_{t_{0}}^{t} f\left(s, \phi_{k-1}(s)\right) d s
$$

If one can demonstrate that a sequence of solutions $\phi_{0}, \phi_{1}, \phi_{2}, \ldots$ converges to some function $\phi(t)$ that satisfies equation (25) then, the argument goes, one has not only proven the existence of a solution to the initial value problem, but has also constructed a formula (however unwieldy) for the solution.

Based on this results we introduce the following iterative operator splitting methods.

\subsection{Iterative Operator Splitting Method}

A method to solve large coupled differential equations is the Waveform-Relaxation scheme.

The iterative method was discussed in [17] and [9]. For the method, there exist Gauss- or Jacobian schemes to decouple at least the schemes more or less effective. To accelerate the schemes, analytical support is important.

We deal with the following ordinary differential equation or assume a semidiscretized partial differential equation:

$$
\begin{aligned}
& u_{t}=f(u, t), \text { in }(0, T), \\
& u(0)=v_{0},
\end{aligned}
$$

where $u=\left(u_{1}, \ldots, u_{m}\right)^{t}$ and $f(u, t)=\left(f_{1}(u, t), \ldots, f_{m}(u, t)\right)^{t}$.

We apply the Waveform-Relaxation method in the Jacobian form for $i=0,1, \ldots m$ and have:

$$
\begin{aligned}
& \frac{\partial u_{1, i}(x, t)}{\partial t}=f_{1}\left(u_{1, i}, u_{2, i-1}, \ldots, u_{m, i-1}\right) \text { with } u_{1, i}\left(t^{n}\right)=u_{1}\left(t^{n}\right) \\
& \frac{\partial u_{2, i}(x, t)}{\partial t}=f_{2}\left(u_{1, i-1}, u_{2, i}, u_{3, i-1} \ldots, u_{m, i-1}\right) \text { with } u_{2, i}\left(t^{n}\right)=u_{2}\left(t^{n}\right) \\
& \vdots \\
& \frac{\partial u_{m, i}(x, t)}{\partial t}=f_{m}\left(u_{1, i-1}, \ldots, u_{m-1, i-1}, u_{m, i}\right) \text { with } u_{m, i}\left(t^{n}\right)=u_{m}\left(t^{n}\right)
\end{aligned}
$$


where for the initialization of the first step we have $u_{1,-1}(t)=u_{1}\left(t^{n}\right), \ldots, u_{m,-1}(t)=$ $u_{m}\left(t^{n}\right)$

We reduce to the operator notation and assume the decomposition into two operators. So we deal with:

$$
\begin{aligned}
\frac{\partial u_{i}}{\partial t} & =A_{1}\left(u_{i}\right)+A_{2}\left(u_{i-1}\right), \text { in }(0, T), \\
u_{i}(0) & =u(0)
\end{aligned}
$$

where $u_{i}=\left(u_{1, i}, \ldots, u_{m, i}\right)$.

We assume a linear part in the diagonal and a nonlinear part in the outerdiagonal parts:

$$
A_{1}=D, A_{2}(u)=L(u)+U(u),
$$

where $D$ is the diagonal part of matrix $A(u)$ and $L(u)+U(u)$ are the outerdiagonal part of $A(u)$.

The iterative splitting method as Waveform-Relaxation method written in the analytical form for $i=0,1, \ldots m$ is:

$$
\begin{aligned}
& u_{i}\left(t^{n}\right)=\exp \left(A_{1}\left(t^{n}-t^{n-1}\right)\right) u\left(t^{n-1}\right)+\int_{t^{n-1}}^{t^{n}} \exp \left(A_{1}\left(t^{n}-s\right) A_{2}\left(u_{i-1}(s)\right) d(37)\right. \\
& \text { with } u_{i}\left(t^{n}\right)=u\left(t^{n}\right),
\end{aligned}
$$

\subsection{Application to a linear outer-diagonal part}

We deal with the following equations:

$$
\begin{aligned}
& \partial_{t} u_{1}=-\lambda_{1} u_{1}+\lambda_{2} u_{2}+\ldots+\lambda_{m} u_{m} \text { in } \Omega \times(0, T), \\
& \vdots \\
& \partial_{t} u_{m}=\lambda_{1} u_{1}+\lambda_{2} u_{2}+\ldots-\lambda_{m} u_{m} \text { in } \Omega \times(0, T), \\
& u(0)=\left(c_{1}, \ldots, c_{m}\right) \in \Omega
\end{aligned}
$$

The algorithm is given with semi-analytical solutions of the reaction equations

$$
\tilde{u}^{k}=\exp (-\Lambda t) \tilde{u}^{0}+\Lambda^{-1}(I-\exp (-\Lambda t)) \tilde{\Lambda} \tilde{u}^{k-1},
$$

where the matrices are given as

$$
\begin{gathered}
\tilde{u}^{k}=\left(\begin{array}{c}
u_{1}^{k} \\
u_{2}^{k} \\
\vdots \\
u_{m}^{k}
\end{array}\right), \\
\tilde{u}^{k-1}=\left(\begin{array}{c}
u_{1}^{k-1} \\
u_{2}^{k-1} \\
\vdots \\
u_{m}^{k-1}
\end{array}\right),
\end{gathered}
$$




$$
\begin{aligned}
\Lambda & =\left(\begin{array}{cccc}
\lambda_{1} & 0 & \ldots & 0 \\
0 & \lambda_{2} & \ldots & 0 \\
\vdots & \ddots & \ddots & \vdots \\
0 & 0 & \ldots & \lambda_{m}
\end{array}\right), \\
\tilde{\Lambda} & =\left(\begin{array}{cccc}
0 & \lambda_{2} & \ldots & \lambda_{m} \\
\lambda_{1} & 0 & \ldots & \lambda_{m} \\
\vdots & \ddots & \ddots & \vdots \\
\lambda_{1} & \lambda_{2} & \ldots & 0
\end{array}\right),
\end{aligned}
$$

The iterative algorithm is given as

Step 1: $\tilde{u}^{0}=\left(c_{0}(x), \ldots, c_{m}(x)\right)^{T}$

Step 2: Solve $\tilde{u}^{1}$ with

$$
\tilde{u}^{1}=\exp (-\Lambda t) \tilde{u}^{0}+\Lambda^{-1}(I-\exp (-\Lambda t)) \tilde{\Lambda} \tilde{u}^{0},
$$

Step k :

$$
\tilde{u}^{k}=\exp (-\Lambda t) \tilde{u}^{0}+\Lambda^{-1}(I-\exp (-\Lambda t)) \tilde{\Lambda} \tilde{u}^{k-1},
$$

The stop-criterion is controlled after each step:

We have the absolute error of the solution-vector $\left|\tilde{u}^{k}-\tilde{u}^{k-1}\right| \leq e r r$ and we finish the algorithm and obtain the results: $u(t)=u^{k}(t)$.

Remark 2. For modification to the Waveform-Relaxation method, we have the following contributions:

1.) Gauss-Seidel Waveform Relaxation Method:

Here we apply the lower matrix for the iteration method.

2.) Block Jacobian Waveform Relaxation Method:

Here we have $2 \times 2$ blocks for the diagonals.

3.) Block Gauss-Seidel Waveform Relaxation Method:

Here we have $2 \times 2$ blocks for the diagonals and the lower matrix.

\subsection{Nonlinear outer-diagonal part}

For nonlinear outer-diagonal parts we have to apply successive approximations given as:

$$
\begin{aligned}
& u_{i}\left(t^{n}\right)=\exp \left(A_{1}\left(t^{n}-t^{n-1}\right) u\left(t^{n-1}\right)+\int_{t^{n-1}}^{t^{n}} \exp \left(A_{1}\left(t^{n}-s\right) A_{2}\left(u_{i-1}(s)\right) d \$ 50\right)\right. \\
& \text { with } u_{i}\left(t^{n}\right)=u\left(t^{n}\right),
\end{aligned}
$$

Because of the diagonal structure of the matrix $A_{1}$ we can write the problem as an m-vector function given as:

$$
\begin{aligned}
& u_{i, j}\left(t^{n}\right)=\exp \left(a_{j j}\left(t^{n}-t^{n-1}\right) u_{j}\left(t^{n-1}\right)+\int_{t^{n-1}}^{t^{n}} \exp \left(a_{j j}\left(t^{n}-s\right) f_{j}\left(u_{i-1, j}(s)\right)\right.\right. \\
& \text { with } u_{i, j}\left(t^{n}\right)=u_{j}\left(t^{n}\right)
\end{aligned}
$$


where $f_{j}\left(u_{i-1, j}(s)\right)$ is the $j$-th row of the outer-diagonal part.

\subsection{Numerical integration schemes}

We have to apply to integrate the equation:

$$
u(t)=\int_{t^{n}}^{t} \tilde{f}(s) d s
$$

1.) Trapezoidal rule: $u(t)=\frac{\Delta t}{2}\left(\tilde{f}\left(t^{n}\right)+\tilde{f}(t)\right)$.

2.) Simpson rule: $u(t)=\frac{\Delta t}{6}\left(\tilde{f}\left(t^{n}\right)+4 \cdot \tilde{f}\left(t^{n}+\frac{1}{2}\left(t-t^{n}\right)\right)+\tilde{f}(t)\right)$, where the values for $\tilde{f}\left(t^{n}+\frac{t-t^{n}}{2}\right)$ are computed with the trapezoidal rule.

3.) Simplified Runge-Kutta method: $u(t)=\frac{\Delta t}{4}\left(\tilde{f}\left(t^{n}\right)+3 \cdot \tilde{f}\left(t^{n}+\frac{2}{3} \cdot\left(t-t^{n}\right)\right)\right)$

4.) Runge-Kutta method: $\frac{d y}{d t}=f(t, y)$ which takes the form

$y_{n+1}=y_{n}+h \sum_{i=1}^{s} b_{i} k_{i}$,

$k_{i}=f\left(t_{n}+c_{i} h, y_{n}+h \sum_{j=1}^{s} a_{i j} k_{j}\right)$.

Implicit trapezoidal rule

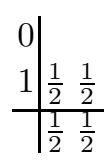

Gauss Runge-Kutta

$$
\begin{array}{c|cc}
\frac{1}{2}-\frac{\sqrt{3}}{6} & \frac{1}{4} & \frac{1}{4}-\frac{\sqrt{3}}{6} \\
\frac{1}{2}+\frac{\sqrt{3}}{6} & \frac{1}{4}+\frac{\sqrt{3}}{6} & \frac{1}{4} \\
\hline & \frac{1}{2} & \frac{1}{2}
\end{array}
$$

Lobatto IIIA

$$
\begin{array}{c|ccc}
0 & 0 & 0 & 0 \\
\frac{1}{2} & \frac{5}{24} & \frac{1}{3} & -\frac{1}{24} \\
1 & \frac{1}{6} & \frac{2}{3} & \frac{1}{6} \\
\hline & \frac{1}{6} & \frac{2}{3} & \frac{1}{6}
\end{array}
$$

Remark 3. Special so called exponential Runge-Kutta Methods are also developed to taken into account the benefit of the exp operators, see [8]

5.) Exponential Runge-Kutta Methods:

To apply a more specific Runge-Kutta method that take into account the exponential functions, we can apply an exponential Runge-Kutta method, see [8]. 
The equation is given as:

$\frac{d y}{d t}=A y+f(t, y)$

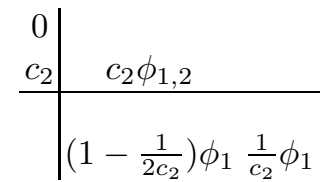

where for $c_{2}=\frac{1}{2}$, we have $b_{1}=0$ and

$\phi_{0}(A \tau)=\exp (A \tau)$

$\phi_{1}(A \tau)=\frac{\exp (A \tau)-I}{A \tau}$

$\phi_{2}(A \tau)=\frac{\phi_{1}(A \tau)-I}{A \tau}$

and

$\phi_{i, j}=\phi_{i, j}(A \tau)=\phi_{i}\left(c_{j} A \tau\right), 2 \leq j \leq s$

and $s$ is the stage of the RK method.

\section{Numerical experiments}

In the next experiments we deal with the kinetics of different precursor gases.

\subsection{First experiment}

We will now compute the following reaction:

$$
\mathrm{SiH}_{2} \rightarrow \mathrm{Si}+\mathrm{H}_{2}
$$

The reaction is of first order and we get the following velocity law, where brackets denote concentrations:

$$
\frac{d\left[\mathrm{SiH}_{2}\right]}{d t}=-k \cdot\left[\mathrm{SiH}_{2}\right]
$$

where the temperature dependent reaction constant $\mathrm{k}$ is given as $k(T)=9.73$. $10^{8} \cdot \exp \left(-261 \frac{\mathrm{kJ}}{\mathrm{mol}} /(R T)\right)$ with $R=8.314472 \frac{\mathrm{J}}{\mathrm{mol} \cdot \mathrm{K}}$. The analytical solution is then given as

$$
\left[\mathrm{SiH}_{2}\right]=\exp (-k(T)) \cdot\left[\mathrm{SiH}_{2}\right]_{0} .
$$

Figure 5 shows the graphs at the Temperatures $573 \mathrm{~K}, 773 \mathrm{~K}$ and $973 \mathrm{~K}$, where the initial condition is $\left[\mathrm{SiH}_{2}, 0\right]_{0}=1 \frac{\mathrm{mol}}{\mathrm{l}}$. We will now compute the following reaction:

$$
\mathrm{SiH}_{4} \rightarrow \mathrm{Si}+2 \mathrm{H}_{2}
$$

The reaction is of first order and we get the velocity law:

$$
\frac{d\left[\mathrm{SiH}_{2}\right]}{d t}=-k \cdot\left[\mathrm{SiH}_{2}\right]
$$


where the temperature dependent reaction constant $\mathrm{k}$ is given as $k(T)=5.66$. $10^{14} \cdot \exp \left(-244 \frac{\mathrm{kJ}}{\mathrm{mol}} /(R T)\right)$ with $R=8.314472 \frac{\mathrm{J}}{\mathrm{mol} \cdot \mathrm{K}}$. The analytical solution is then given as

$$
\left[\mathrm{SiH}_{4}\right]=\exp (-k(\mathrm{~T})) \cdot\left[\mathrm{SiH}_{4}\right]_{0} .
$$

Figure 6 shows the graphs at the Temperatures $573 \mathrm{~K}, 773 \mathrm{~K}$ and $973 \mathrm{~K}$, where the initial condition is $\left[\mathrm{SiH}_{4}\right]_{0}=1 \frac{\mathrm{mol}}{\mathrm{l}}$.

We will now investigate the consecutive decay of Tetramethylsilane (TMS):

$$
\begin{aligned}
& \mathrm{Si}\left(\mathrm{CH}_{3}\right)_{4} \rightarrow \cdot \mathrm{Si}\left(\mathrm{CH}_{3}\right)_{3}+\cdot \mathrm{CH}_{3} \\
& \cdot \mathrm{Si}\left(\mathrm{CH}_{3}\right)_{3} \rightarrow \ddot{\mathrm{Si}}\left(\mathrm{CH}_{3}\right)_{2}+\mathrm{CH}_{3}
\end{aligned}
$$

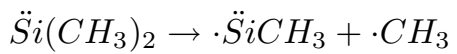

We assume the following velocity laws:

$$
\begin{aligned}
& \left.\frac{d\left[\mathrm{Si}\left(\mathrm{CH}_{3}\right)_{4}\right]}{d t}=-k \cdot\left[\mathrm{Si}_{(\mathrm{CH}}\right)_{4}\right] \\
& \frac{d\left[\cdot \mathrm{Si}\left(\mathrm{CH}_{3}\right)_{3}\right]}{d t}=k \cdot\left[\mathrm{Si}\left(\mathrm{CH}_{3}\right)_{4}\right]-0.9 k \cdot\left[\cdot \mathrm{Si}\left(\mathrm{CH}_{3}\right)_{3}\right] \\
& \frac{d\left[\ddot{\mathrm{S} i}\left(\mathrm{CH}_{3}\right)_{2}\right]}{d t}=0.9 k \cdot\left[\cdot \mathrm{Si}\left(\mathrm{CH}_{3}\right)_{3}\right]-0.85 k \cdot\left[\ddot{\mathrm{S} i}\left(\mathrm{CH}_{3}\right)_{2}\right] \\
& \frac{d\left[\cdot \ddot{\mathrm{Si}} i\left(\mathrm{CH}_{3}\right)\right]}{d t}=0.85 k \cdot\left[\ddot{\mathrm{S}} i\left(\mathrm{CH}_{3}\right)_{2}\right],
\end{aligned}
$$

where the temperature dependent reaction constant $\mathrm{k}$ is given as $k(T)=2 \cdot 10^{14}$. $\exp \left(-283 \frac{k J}{\mathrm{~mol}} /(R T)\right)$ with $R=8.314472 \frac{\mathrm{J}}{\mathrm{mol} \cdot \mathrm{K}}$. Figure 7 shows the graphs at the Temperatures $573 \mathrm{~K}, 773 \mathrm{~K}$ and $973 \mathrm{~K}$, where the initial condition is $\left[\mathrm{SiH}_{2}\right]_{0}=$ $1 \frac{\mathrm{mol}}{l}$.

In table 2 (trapezoidal rule), table 3 (Simpson rule) and table 4 (simplified Runge-Kutta method) we present the computed errors $\left(1 / n \cdot \sum_{n=0}^{T} \mid c_{i}^{k}\left(t^{n}\right)-\right.$ $c^{k}\left(t^{n}\right) \mid /\left(c^{k}\left(t^{n}\right)\right)$, n-number of time steps, T-end time, i-iteration, k-component) in comparison to the exact solution.

Remark 4. Based on the different temperatures, we obtain a slow reaction process to low temperatures and a fast reaction process to high temperatures. So a temperature between $700-900 K$ is appropriate for the reaction process time which is about $2 h$. Here the remaining time in the reaction chamber is important to have stable deposition rates.

\subsection{Second experiment}

In the second experiment we extend the kinetic reactions to MCS (precursor gas).

For the formation of $\mathrm{SiC}$ via MCS we can formulate the following system of 


\begin{tabular}{c|c|c|c}
$c_{i}$ & iteration & number of time steps & error \\
\hline 1 & $\geq 1$ & 10 & $3.79 \cdot 10^{-11}$ \\
1 & $\geq 1$ & 50 & $9.87 \cdot 10^{-10}$ \\
1 & $\geq 1$ & 100 & $2.73 \cdot 10^{-9}$ \\
\hline \hline 2 & $\geq 2$ & 10 & 0.0003437234605 \\
2 & $\geq 2$ & 50 & 0.00001374968496 \\
2 & $\geq 2$ & 100 & 0.000003438763040 \\
\hline \hline 3 & $\geq 3$ & 10 & 0.005750371509 \\
3 & $\geq 3$ & 50 & 0.0003643759657 \\
3 & $\geq 3$ & 100 & 0.0001058235010
\end{tabular}

Table 2. Errors of the computations for the decay of TMS via trapezoidal rule $\left(c_{1}=\right.$ $\left.\mathrm{Si}\left(\mathrm{CH}_{3}\right)_{4}, c_{2}=\cdot \mathrm{Si}\left(\mathrm{CH}_{3}\right)_{3}, c_{3}=\ddot{S} i\left(\mathrm{CH}_{3}\right)_{2}\right)$

\begin{tabular}{c|c|c|c}
$c_{i}$ & iteration & number of time steps & error \\
\hline 1 & $\geq 1$ & 5 & $1.83 \cdot 10^{-10}$ \\
1 & $\geq 1$ & 25 & $7.52 \cdot 10^{-10}$ \\
1 & $\geq 1$ & 50 & $9.87 \cdot 10^{-10}$ \\
\hline \hline 2 & $\geq 2$ & 5 & $9.44 \cdot 10^{-8}$ \\
2 & $\geq 2$ & 25 & $7.83 \cdot 10^{-10}$ \\
2 & $\geq 2$ & 50 & $3.26 \cdot 10^{-10}$ \\
\hline \hline 3 & $\geq 3$ & 5 & 0.0002280476352 \\
3 & $\geq 3$ & 25 & 0.000009163439105 \\
3 & $\geq 3$ & 50 & 0.000002291716311
\end{tabular}

Table 3. Errors of the computations for the decay of TMS via Simpson rule $\left(c_{1}=\right.$ $\left.\mathrm{Si}\left(\mathrm{CH}_{3}\right)_{4}, c_{2}=\cdot \mathrm{Si}\left(\mathrm{CH}_{3}\right)_{3}, c_{3}=\ddot{S} i\left(\mathrm{CH}_{3}\right)_{2}\right)$

\begin{tabular}{c|c|c|c}
$c_{i}$ & iteration & number of time steps & error \\
\hline 1 & $\geq 1$ & 4 & $8.65 \cdot 10^{-10}$ \\
1 & $\geq 1$ & 17 & $1.46 \cdot 10^{-9}$ \\
1 & $\geq 1$ & 34 & $1.97 \cdot 10^{-9}$ \\
\hline \hline 2 & $\geq 2$ & 4 & 0.04012194969 \\
2 & $\geq 2$ & 17 & 0.009444739948 \\
2 & $\geq 2$ & 34 & 0.004722463966 \\
\hline \hline 3 & $\geq 3$ & 4 & 0.2205151890 \\
3 & $\geq 3$ & 17 & 0.09236895448 \\
3 & $\geq 3$ & 34 & 0.05624757203
\end{tabular}

Table 4. Errors of the computations for the decay of TMS via simplified Runge-Kutta method $\left(c_{1}=\mathrm{Si}\left(\mathrm{CH}_{3}\right)_{4}, c_{2}=\cdot \mathrm{Si}\left(\mathrm{CH}_{3}\right)_{3}, c_{3}=\ddot{S} i\left(\mathrm{CH}_{3}\right)_{2}\right)$ 
ode's:

$$
\begin{aligned}
& \frac{d\left[\mathrm{CH}_{3} \mathrm{SiCl}_{3}\right]}{d t}=-k_{1} \cdot\left[\mathrm{CH}_{3} \mathrm{SiCl}_{3}\right]-k_{3} \cdot\left[\mathrm{CH}_{3} \mathrm{SiCl}_{3}\right]\left[\cdot \mathrm{CH}_{3}\right] \\
& \frac{d\left[\cdot \mathrm{CH}_{3}\right]}{d t}=k_{1} \cdot\left[\mathrm{CH}_{3} \mathrm{SiCl}_{3}\right]-k_{2} \cdot\left[\cdot \mathrm{CH}_{3}\right]\left[\mathrm{H}_{2}\right]- \\
& -k_{3} \cdot\left[\mathrm{CH}_{3} \mathrm{SiCl}_{3}\right]\left[\cdot \mathrm{CH}_{3}\right] \\
& \frac{d\left[\cdot \mathrm{SiCl}_{3}\right]}{d t}=k_{1} \cdot\left[\mathrm{CH}_{3} \mathrm{SiCl}_{3}\right]-k_{4} \cdot\left[\cdot \mathrm{SiCl}_{3}\right][\mathrm{HCl}]-k_{5} \cdot\left[\cdot \mathrm{SiCl}_{3}\right]^{2}+ \\
& +k_{7} \cdot\left[\mathrm{SiCl}_{4}\right][\cdot \mathrm{H}] \\
& \frac{d\left[\mathrm{H}_{2}\right]}{d t}=-k_{2} \cdot\left[\cdot \mathrm{CH}_{3}\right]\left[\mathrm{H}_{2}\right] \\
& \frac{d[\cdot H]}{d t}=k_{2} \cdot\left[\cdot C H_{3}\right]\left[H_{2}\right]-k_{7} \cdot\left[\mathrm{SiCl}_{4}\right][\cdot H] \\
& \frac{d\left[\mathrm{CH}_{4}\right]}{d t}=k_{2} \cdot\left[\cdot \mathrm{CH}_{3}\right]\left[\mathrm{H}_{2}\right]+k_{3} \cdot\left[\mathrm{CH}_{3} \mathrm{SiCl}_{3}\right]\left[\cdot \mathrm{CH}_{3}\right]- \\
& -k_{8} \cdot\left[\ddot{S i C l} l_{2}\right]\left[\mathrm{CH}_{4}\right] \\
& \frac{d[\mathrm{HCl}]}{d t}=k_{6}\left[\mathrm{HSiCl}_{3}\right]+k_{7} \cdot\left[\mathrm{SiCl}_{4}\right][\cdot \mathrm{H}]+k_{8} \cdot\left[\ddot{S i C l} \mathrm{Cl}_{2}\right]\left[\mathrm{CH}_{4}\right]- \\
& -k_{4} \cdot\left[\cdot \mathrm{SiCl}_{3}\right][\mathrm{HCl}] \\
& \frac{d\left[\mathrm{HSiCl}_{3}\right]}{d t}=k_{4} \cdot\left[\cdot \mathrm{SiCl}_{3}\right][\mathrm{HCl}]-k_{6}\left[\mathrm{HSiCl}_{3}\right] \\
& \frac{d\left[\mathrm{SiCl}_{4}\right]}{d t}=k_{5} \cdot\left[\cdot \mathrm{SiCl}_{3}\right]^{2}-k_{7} \cdot\left[\mathrm{SiCl}_{4}\right][\cdot \mathrm{H}] \\
& \frac{d\left[\ddot{S} i C l_{2}\right]}{d t}=k_{5} \cdot\left[\cdot S i C l_{3}\right]^{2}-k_{8} \cdot\left[\ddot{S} i C l_{2}\right]\left[C H_{4}\right]
\end{aligned}
$$

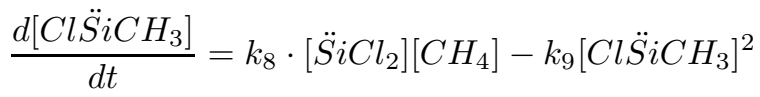

$$
\begin{aligned}
& \frac{d\left[\dot{S} i \mathrm{HCl} \dot{C} H_{2}\right]}{d t}=k_{9} \cdot\left[\mathrm{Cl} \ddot{S} i C H_{3}\right]^{2}
\end{aligned}
$$

Such equation systems are stiff and can only be solved with special ODE solvers.

Remark 5. In the more extended kinetic reactions, we have qualitatively the same results. The stiffness of the equations are more delicate, because we have scale ranges about $10^{25}$.

Because the parameters $k_{5}, k_{8}$ and $k_{9}$ are very large in relation to the other coefficients and because of the huge effort $\left(\Delta t \leq \min 1 / k_{i}\right.$, with $\left.i=1,2 \ldots, 9\right)$ in computing a solution, we use the principle of the quasi-stationary state (see [22]) to reduce the system of odes. As a result we obtain a reduced reaction scheme and a reduced ode system:

$$
\begin{aligned}
& \mathrm{CH}_{3} \mathrm{SiCl}_{3} \stackrel{k_{1}}{\longrightarrow} \cdot \mathrm{CH}_{3}+\frac{1}{2} \mathrm{SiCl}_{4}+\frac{1}{2} \ddot{\mathrm{S}} i \mathrm{Cl}_{2} \\
& \cdot \mathrm{CH}_{3}+\mathrm{H}_{2} \stackrel{k_{2}}{\longrightarrow} \mathrm{CH}_{4}+\cdot \mathrm{H}
\end{aligned}
$$




$$
\begin{array}{r}
\cdot \mathrm{CH}_{3}+\mathrm{CH}_{3} \mathrm{SiCl}_{3} \stackrel{k_{3}}{\longrightarrow} \mathrm{CH}_{4}+\mathrm{Cl}_{3} \mathrm{SiC} \mathrm{H}_{2} \\
\frac{1}{2} \mathrm{SiCl}_{4} \stackrel{k_{7}}{\longrightarrow} \frac{1}{2} \ddot{\mathrm{Si}} \mathrm{Cl} l_{2}+\mathrm{HCl}
\end{array}
$$

$$
\begin{aligned}
\frac{d\left[\mathrm{CH}_{3} \mathrm{SiCl}_{3}\right]}{d t}= & -k_{1} \cdot\left[\mathrm{CH}_{3} \mathrm{SiCl}_{3}\right]-k_{3} \cdot\left[\mathrm{CH}_{3} \mathrm{SiCl}_{3}\right]\left[\cdot \mathrm{CH}_{3}\right] \\
\frac{d\left[\cdot \mathrm{CH} H_{3}\right]}{d t}= & k_{1} \cdot\left[\mathrm{CH}_{3} \mathrm{SiCl}_{3}\right]-k_{2} \cdot[\cdot \mathrm{CH}]\left[\mathrm{H}_{2}\right]- \\
& -k_{3} \cdot\left[\mathrm{CH}_{3} \mathrm{SiCl}_{3}\right]\left[\cdot \mathrm{CH} \mathrm{H}_{3}\right] \\
\frac{d\left[\mathrm{H}_{2}\right]}{d t}= & -k_{2} \cdot\left[\cdot \mathrm{CH}_{3}\right]\left[\mathrm{H}_{2}\right] \\
\frac{d[\cdot H]}{d t}= & k_{2} \cdot\left[\cdot \mathrm{CH}_{3}\right]\left[\mathrm{H}_{2}\right]-k_{7} \cdot\left[\mathrm{SiCl}_{4}\right][\cdot \mathrm{H}] \\
\frac{d[\mathrm{SiCl}]}{d t}= & \frac{1}{2} k_{1} \cdot\left[\mathrm{CH}_{3} \mathrm{SiCl}_{3}\right]-\frac{1}{2} k_{7} \cdot\left[\mathrm{SiCl}_{4}\right][\cdot \mathrm{H}] \\
\frac{d[\mathrm{CH}]}{d t}= & k_{2} \cdot\left[\cdot \mathrm{CH}_{3}\right]\left[\mathrm{H}_{2}\right]+k_{3} \cdot\left[\mathrm{CH}_{3} \mathrm{SiCl}_{3}\right][\cdot \mathrm{CH}] \\
\frac{d[\ddot{\mathrm{SiCl}}]}{d t}= & \frac{1}{2} k_{1} \cdot\left[\mathrm{CH}_{3} \mathrm{SiCl}_{3}\right]+\frac{1}{2} k_{7} \cdot\left[\mathrm{SiCl}_{4}\right][\cdot \mathrm{H}]
\end{aligned}
$$

Because the reaction of $\ddot{S} i l_{2}$ and $\mathrm{CH}_{4}$ to $\mathrm{SiC}$ is very fast, the concentrations of these two components determine the final concentration of $\mathrm{SiC}$. Therefore the lesser concentration of these two components equals the concentration of the $\mathrm{SiC}$ We applied the trapezoidal rule, see Section 3 to solve the system of odes. The Figures 8, 9 and 10 show the results for the all concentrations at the temperatures $573 \mathrm{~K}, 773 \mathrm{~K}$ and $973 \mathrm{~K}$.

\section{Conclusions and Discussions}

We present a model to simulate the kinetic processes of precursor gases on a CVD plasma reactor. We solve the nonlinear differential equations with iterative methods and accelerate the solver processes.

Based on the numerical experiments we could obtain the reaction time of the full reaction kinetic of different precursor gases.

\section{References}

1. D.J. Christie. Target material pathways model for high power pulsed magnetron sputtering. J.Vac.Sci. Technology, 23:2, 330-335, 2005.

2. P. Eklund, M. Beckers, J. Frodelius, H. Högberg, and L. Hultman. Magnetron sputtering of Ti3SiC2 tin films from a compound target. JVST A, 25(5):1381-1388, 2007. 
3. L.C. Evans. Partial Differential Equations. Graduate Studies in Mathematics, Volume 19, AMS, 1998.

4. J. Geiser. Numerical Simulation of a Model for Transport and Reaction of Radionuclides. Proceedings of the Large Scale Scientific Computations of Engineering and Environmental Problems, Sozopol, Bulgaria, 2001.

5. J. Geiser. Discretization methods with analytical solutions for convection-diffusiondispersion-reaction-equations and applications. Journal of Engineering Mathematics, published online, Oktober 2006.

6. J. Geiser. Discretisation and Solver Methods with Analytical Methods for Advection-Diffusion-reaction Equations and 2D Applications. Journal of Porous Media, Begell House Inc., Redding, USA, accepted March, 2008.

7. M.K. Gobbert and C.A. Ringhofer. An asymptotic analysis for a model of chemical vapor deposition on a microstructured surface. SIAM Journal on Applied Mathematics, 58, 737-752, 1998.

8. M. Hochbruck and A. Ostermann. Expenential Runge-Kutta methods for parabolic problems. Applied Numerical Mathematics, 53, 323-339, 2005.

9. J. Jansen. Acceleration of waveform relaxation methods for linear ordinary and partial differential equations PhD-thesis, Department of Computer Science, K.U.Leuven, Belgium, 1999.

10. H.H. Lee. Fundamentals of Microelectronics Processing McGraw-Hill, New York, 1990.

11. S. Middleman and A.K. Hochberg. Process Engineering Analysis in Semiconductor Device Fabrication McGraw-Hill, New York, 1993.

12. O. Nevanlinna. Remarks on Picard-Lindelöf Iteration, Part I. BIT, 29, 328-346, 1989.

13. O. Nevanlinna. Remarks on Picard-Lindelöf Iteration, Part II. BIT, 29, 535-562, 1989.

14. M. Ohring. Materials Science of Thin Films. Academic Press, San Diego, New York, Boston, London, Second edition, 2002.

15. P.J. Roache. A flux-based modified method of characteristics. Int. J. Numer. Methods Fluids, 12:12591275, 1992.

16. T.K. Senega and R.P. Brinkmann. A multi-component transport model for nonequilibrium low-temperature low-pressure plasmas. J. Phys. D: Appl.Phys., 39, 1606-1618, 2006.

17. S. Vandewalle. Parallel Multigrid Waveform Relaxation for Parabolic Problems. B.G. Teubner, Stuttgart, 1993.

18. Source for kinetic rate: http://kinetics.nist.gov/kinetics/Detail?id=1994OST/ALL69957003:1

19. Source for kinetic rate: http://kinetics.nist.gov/kinetics/Detail?id=1996KNY/BEN1134611354:2

20. Source for kinetic rate: http://kinetics.nist.gov/kinetics/Detail?id=1966KER/SLA104:1

21. Source for kinetic rate: http://kinetics.nist.gov/kinetics/Detail?id=1992CHE12021206:2, http://www.wiley-vch.de/contents/jc_2212/2006/fp6468_s.pdf

22. G. Wedler. Lehrbuch der Physikalischen Chemie. Wiley-VCH, Weinheim, Fourth edition 1997

23. Source for kinetic rate: http://kinetics.nist.gov/kinetics/Detail?id=2001WAL/DAT20152022:15

24. Source for kinetic rate: http://kinetics.nist.gov/kinetics/Detail?id=1997CAT/WOI469$472: 1$ 
25. W.G. Zhang, K. J. Hüttinger. CVD of SiC from Methyltrichlorosilane. Part II: Composition of the Gas Phase and the Deposit. Chem. Vap. Deposition, 7, No. 4, 2001 

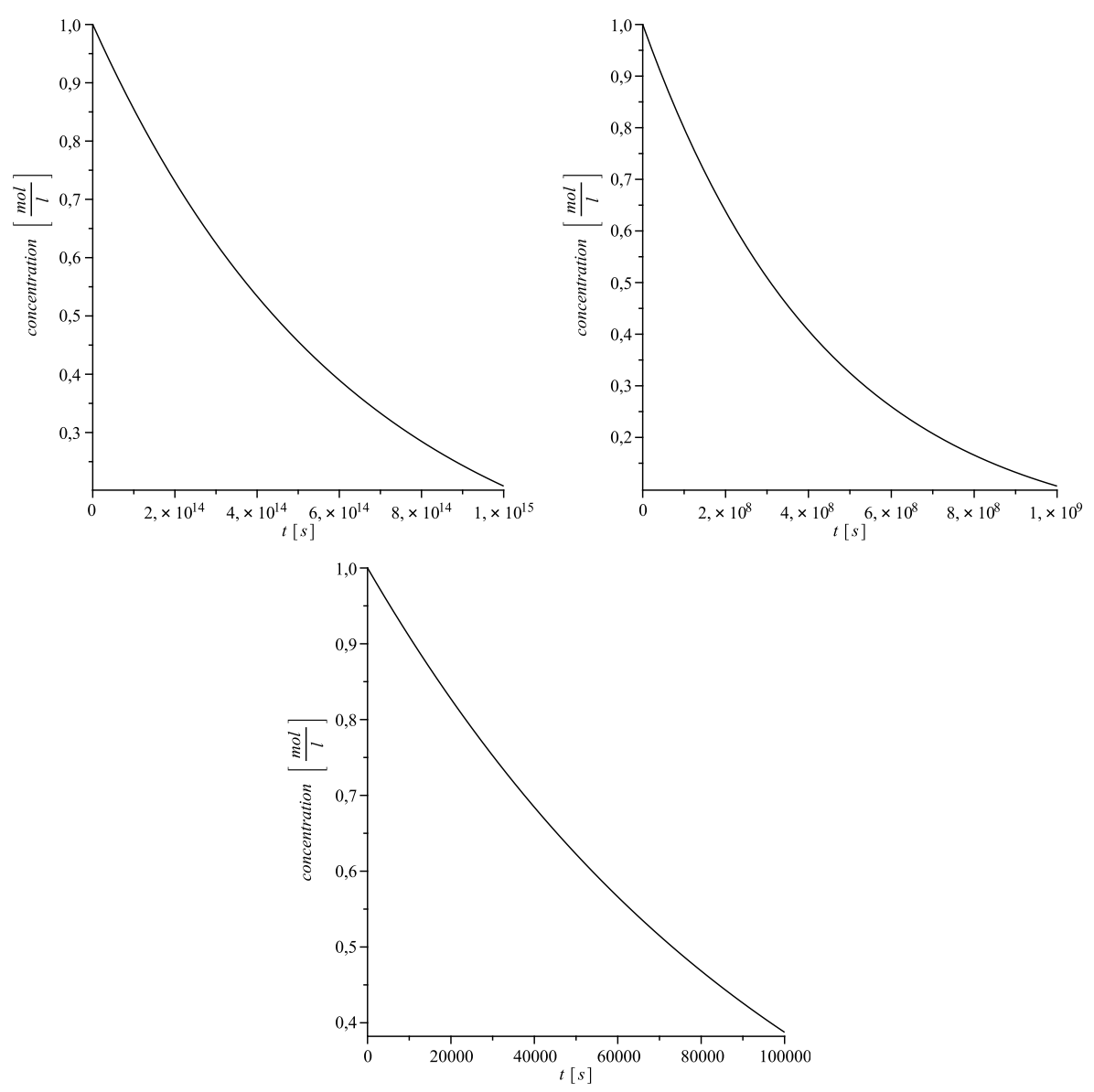

Fig. 5. Decay of $\mathrm{SiH}_{2}$ at the temperatures $573 \mathrm{~K}$ (upper left), $773 \mathrm{~K}$ (upper right) and 973K (lower center) 

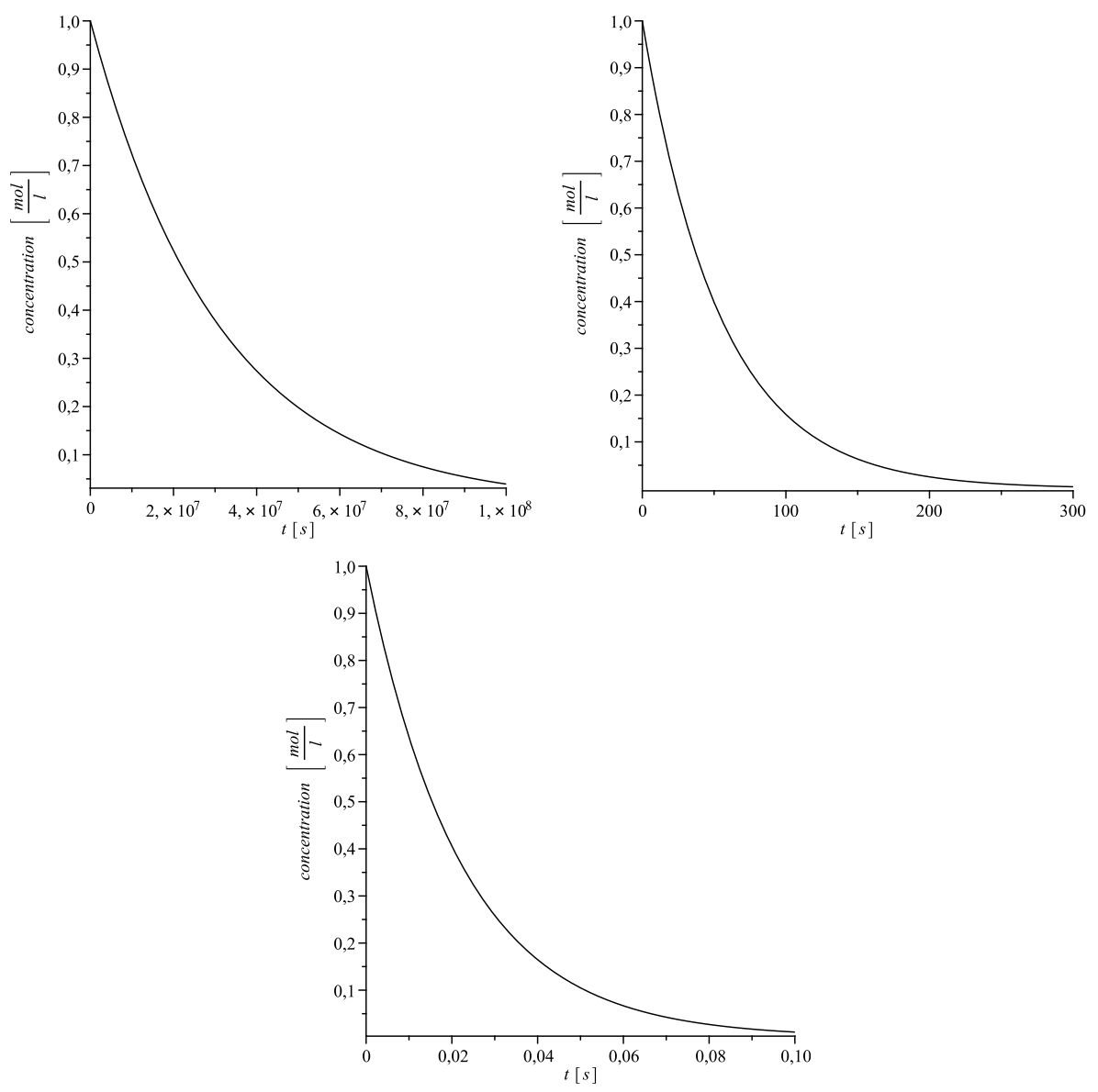

Fig. 6. Decay of $\mathrm{SiH}_{4}$ at the temperatures $573 \mathrm{~K}$ (upper left), 773 (upper right) and 973K (lower center) 

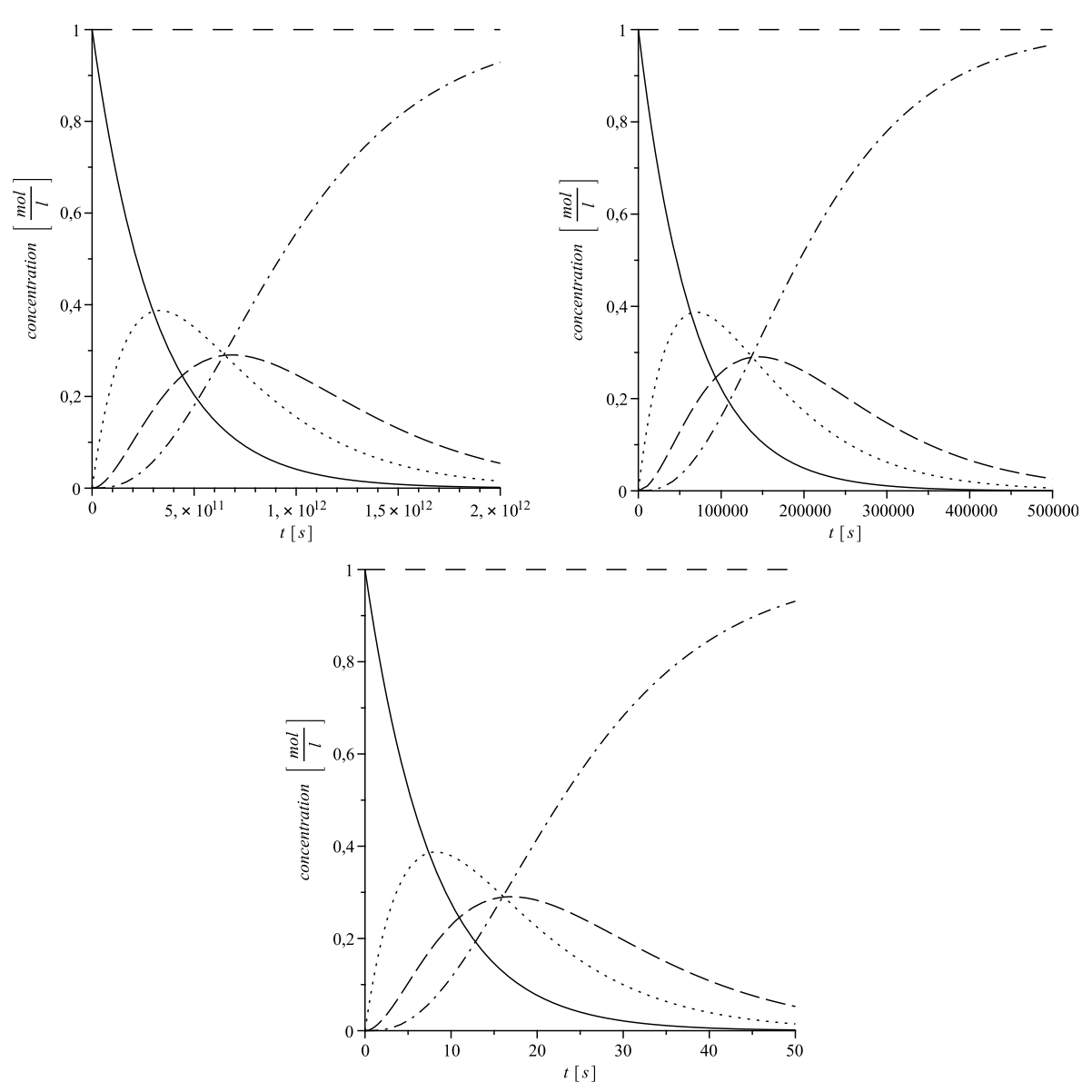

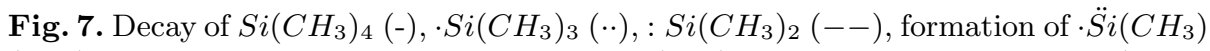
$(\cdot-\cdot)$ and the summary of all concentrations $(-\quad-)$ at the temperatures $573 \mathrm{~K}$ (upper left), $773 \mathrm{~K}$ (upper right) and $973 \mathrm{~K}$ (lower center) 

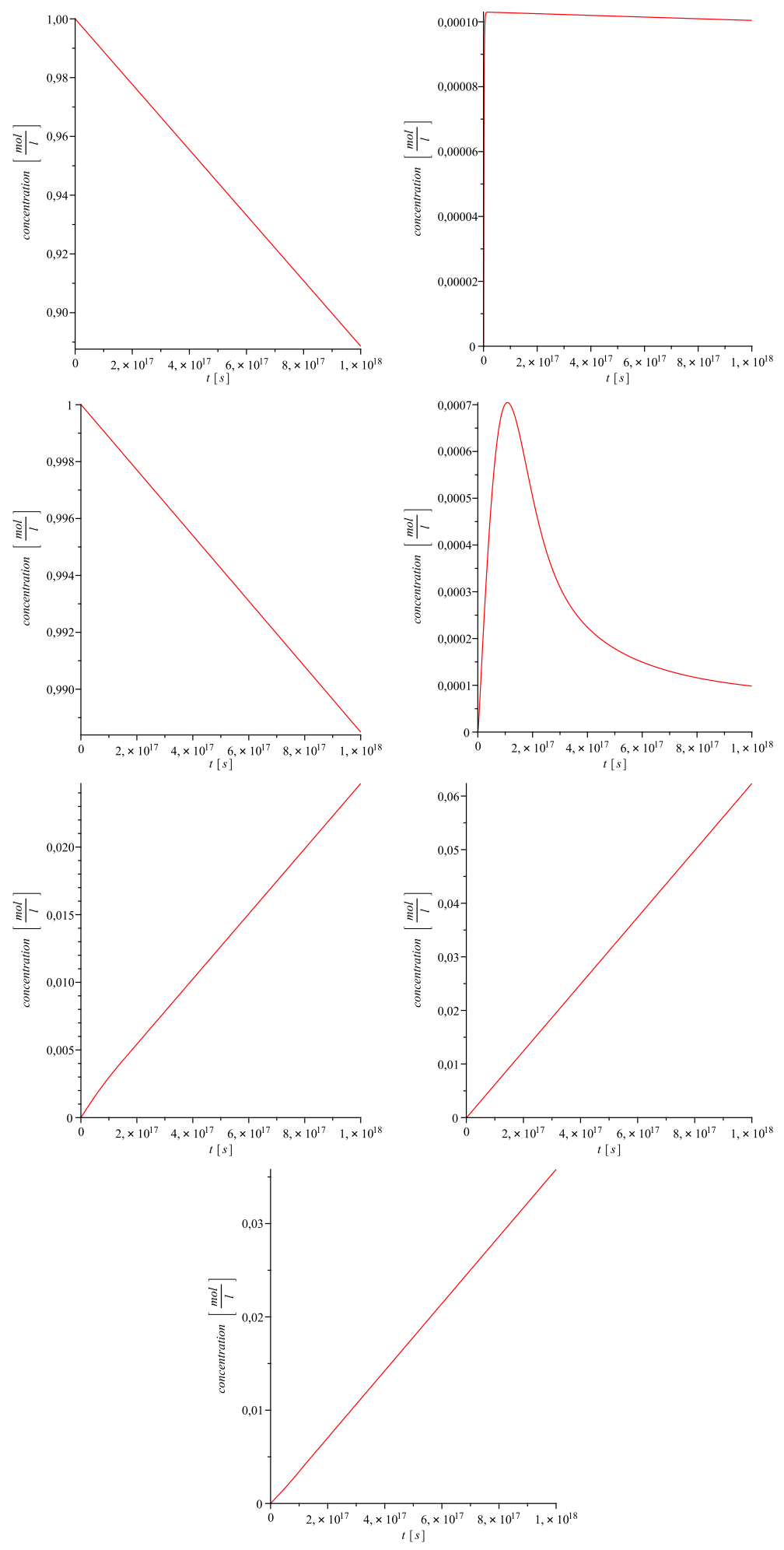

Fig. 8. Concentration of MTS (upper left), $\mathrm{CH}_{3}$ (upper right), $\mathrm{H}_{2}$ (center left), $\cdot H$ (center right), $\mathrm{SiCl}_{4}$ (lower left), $\mathrm{CH}_{4}$ (lower right) and $\ddot{S i C l}_{2}$ (lower center) at $573 \mathrm{~K}$ 

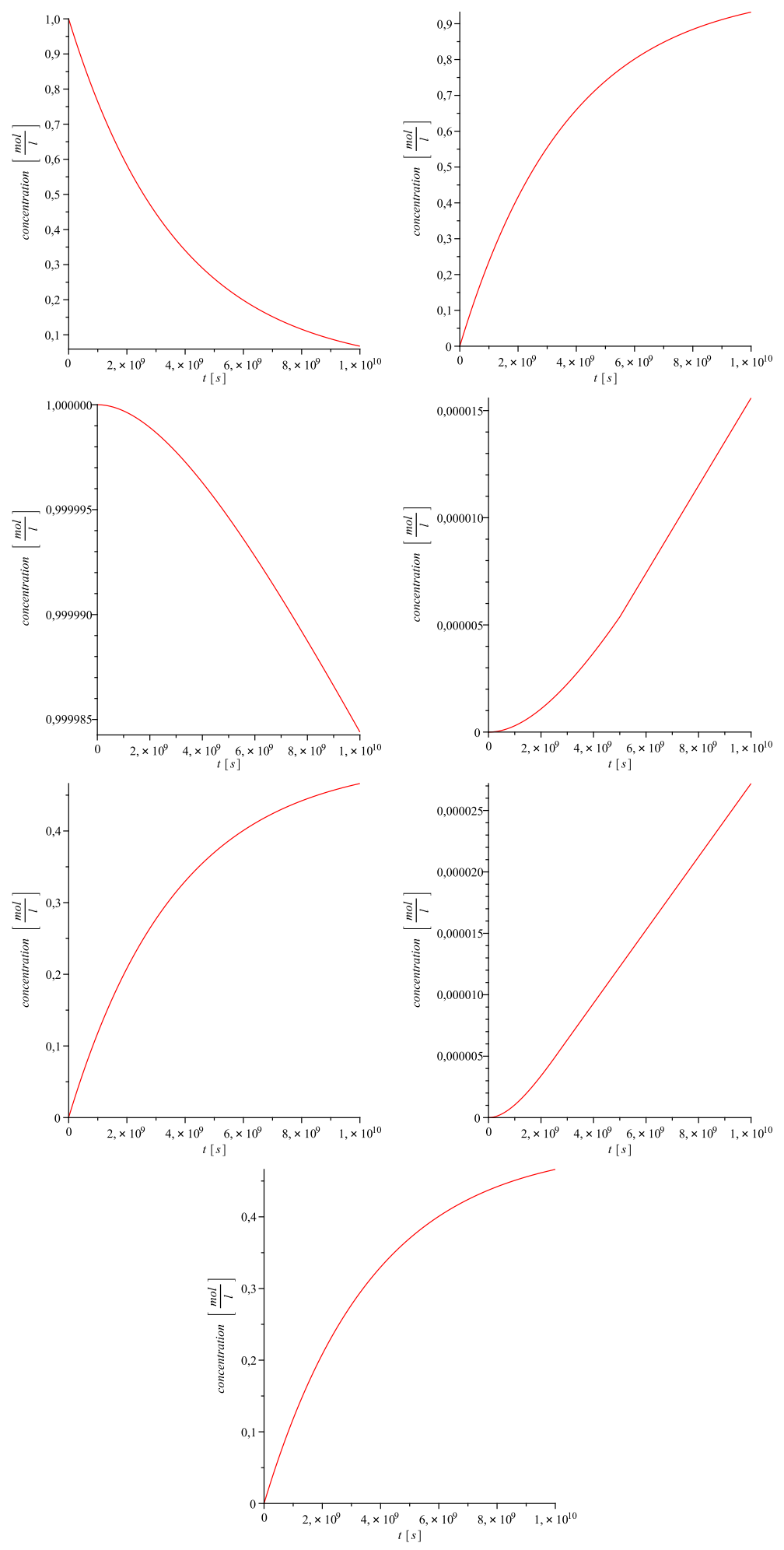

Fig. 9. Concentration of MTS (upper left), $\mathrm{CH}_{3}$ (upper right), $\mathrm{H}_{2}$ (center left), $\cdot H$ (center right), $\mathrm{SiCl}_{4}$ (lower left), $\mathrm{CH}_{4}$ (lower right) and $\ddot{\mathrm{SiCl}} \mathrm{C}_{2}$ (lower center) at $773 \mathrm{~K}$ 

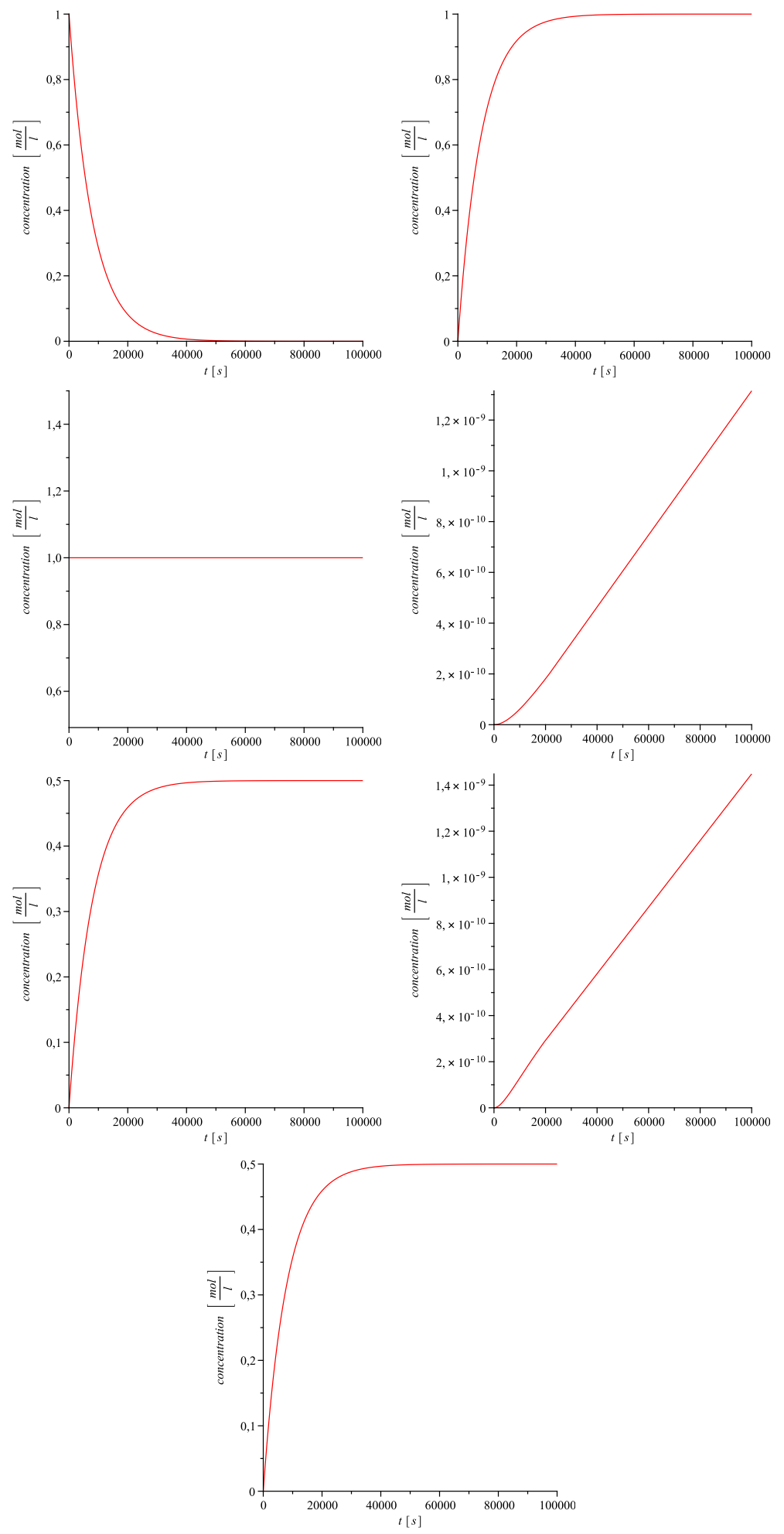

Fig. 10. Concentration of MTS (upper left), $\mathrm{CH}_{3}$ (upper right), $\mathrm{H}_{2}$ (center left), $\cdot H$ (center right), $\mathrm{SiCl}_{4}$ (lower left), $\mathrm{CH}_{4}$ (lower right) and $\mathrm{SiCl}_{2}$ (lower center) at $973 \mathrm{~K}$ 